\title{
Effect of Aromatherapy Massage on Postoperative Sleep Pattern Among School Age Children
}

\author{
Sabah A. Ahmed ${ }^{1}$, Ibrahim A. Ibrahim ${ }^{2}$, Amal A.Mobarak ${ }^{3}$ \& Atyat M. Hassan ${ }^{4}$. \\ Head Nurse of Infection Control Unit at Assuit University Children Hospital, Egypt. \\ 1. Professor of Pediatric Surgery, Faculty of Medicine, Assuit University, Egypt. \\ 2. Assistant Professor of Pediatric Nursing, Faculty of Nursing, Assuit University, Egypt. \\ 3. Lecturer of Pediatric Nursing, Faculty of Nursing, Assiut University, Egypt.
}

\begin{abstract}
Background. Aromatherapy is one of the non-pharmacological methods, it is safe and effective for improve sleep pattern postoperative. Aim: This study was aimed to determine the effect of aromatherapy massage on postoperative sleep pattern among school age children. Design: A quasi-experimental research design was utilized. Setting: The study was conducted at the pediatric surgical unit in Assiut University Children Hospital. Subjects: It included 100 school age children suffer from postoperative poor sleep pattern. It was divided into two groups, experimental group (50 children who received aromatherapy massage beside the hospital routine care) and control group (50 children who received hospital routine ward care).Tools:Two tools were used to collect necessary data which included structured interview questionnaire for personal data and sleep assessment scale. Results: The results showed that they are statistical significant differences between the two groups in pretest, first posttest, and second posttest mean score $(11.66 \pm 2.54,9.50 \pm 0.97$ and $5.80 \pm 0.70)$ respectively as regard sleep pattern. Conclusion: Aromatherapy massage with lavender oil may be an effective therapeutic option for postoperative sleep pattern. There is a significant positive effect of aromatherapy. Recommendation: Using aromatherapy massage as routine interventions for improving postoperative poor sleep pattern in children.
\end{abstract}

\section{Keywords: Aromatherapy Massage, School Age Children \& Sleep Pattern.}

\section{Introduction}

Sleep, which is one of the vital necessities, is crucialin sustaining the physiological and psychological welfare of individuals (Akca Ay, 2012) Hospitalized patients frequently experience sleep disorders for many reasons such as physical condition, medication, fear of death, light, environmental noise, unpleasant odours, foreign instruments, nursing interventions, invasive procedures, complications of disease, loss of privacy and staying away from family (Hajibagheri et al., 2014). Children stay awake for a significant amount of time, they cannot benefit from the therapeutic effects of sleep. Inadequate and unsatisfactory sleep precludes healing by having negative effects on the immune system, wound healing process and cognitive functions of individuals as well as increasing their level of stress and anxiety (Lytle et al., 2014).

The prevalence of sleep disorder is different in international studies and has been reported between 1 and $43 \%$ in school age children (Badin et al., 2016).

One of the non-pharmacological approaches used for sleep disorders is aromatherapy, which is practiced with essential oils from plants via both direct intervention to the skin which is amore effective method (Moeini et al., 2010, Ozdemir, Oztunc,
2013 \& Bikmoradi et al., 2014). Aromatherapy is used for depression, anxiety, relaxation and disorders related with sleep and stress (Lytle et al., 2014). Among the claims made for lavender essential oil, which is commonly used in aromatherapy, are its impact on amygdala and its relaxing, sedative effects and carminative (smooth muscle relaxing) qualities, thus affecting sleep quality, as well as its antibacterial, antifungal, antidepressive and stressreducing qualities. It is also claimed to be the least toxic and allergenic among essential oils (Cho et al., 2013 \& Bikmoradi et al., 2014).

The benefits of lavender's aroma showed that linalool and linalyl acetate present in this plant can stimulate parasympathetic system. In addition, linalyl acetate has narcotic effects and linalool acts as a sedative. This herb improves the heart function and as a circulatory stimulant, it has beneficial effects on coronary blood flow. lavender essential oil had a positive effect on the quality of sleep and anxiety (Fayazi et al., 2011, Bikmoradi et al., 2014 \& Lytle et al., (2014).

Sleep disorders are treated using both pharmacological and non-pharmacological methods. Sedative-hypnotic agents used in pharmacological treatments can increase the quality of sleep significantly; 
however, it is stated that these drugs have side effects, cause addiction and do not provide adequate sleep (Kurt \& Enc, 2013, Hajibagheri et al., 2014). Therefore, it is essential to employ and implement non-pharmacological methods that are safer and have fewer side effects than the pharmacological methods. The quality of sleep pattern after the intervention was significantly different.

Massage therapy is the most commonly used form of complementary medicine and is an easy, safe, noninvasive, and relatively inexpensive (Babaee et al., 2012). One theory about foot reflexology massage is that psychological stress is responsible for $75 \%$ of problems and health complications in humans. More than 7000 nerves exist in each foot; when manipulated by foot and hand massage, these are stimulated to reduce the stress and relax the body, resulting in body equilibrium. In Chinese medicine, massage is carried out to improve life energy through the release of serotonin and melatonin neurotransmitter mediators, which decreases fatigue, resolves depression and improves sleep pattern (Mardas et al., 2013).

Nurse play an important role to assist the child and their parents when using the massage technique in order to make sure that they are using the technique correctly (Terri \& Susan, 2013). Nurses must be able to adequately assess sleep pattern severity, understand how to monitor physiologic changes associated with sleep pattern and its treatment, and be prepared to address the psychosocial experiences accompanying sleep pattern. It is important for nurses to be aware of relevant research and evidence-based guidelines that are available to guide them in sleep pattern assessments and management (Habich et al., 2012).

\section{Significance of the study}

Aromatherapy is one of the most rapidly expanding areas among complementary therapy. Complementary therapies may have an important role in holistic pediatrics sleep pattern management (Browne \& Flanigan, 2007). Uncontrolled sleep pattern leading to increased hospital stay, stress ulcer, rigidity, muscle contraction, increase the rate of postoperative complications (e.g. atelectasis, pneumonia, thromboembolism, depressed immune function, increase risk of delayed recovery, development of sleep disrupt after discharge and prolonged healing process.

\section{Aim of the Study}

The aim of this study was to assess the effect of aromatherapy massage on postoperative sleep disorders among school age children.

\section{Research Hypotheses}

The mean posttest sleep pattern score of the experimental group will be significantly lower than mean pretest sleep pattern score.

\section{Subjects \& Method \\ Research Design}

A Quasi experimental research design was utilized in this study.

\section{Setting}

The study was conducted at the pediatric surgical unit in Assiut University Children Hospital which served the Upper Egypt from Elfum to Aswan.

\section{Subjects}

A convenience sample of 100 children from 6-12 years had postoperative sleep pattern selected from the previous setting. The study subjects were divided randomly into two groups: Experimental group (50 children who received aromatherapy massage beside the hospital routine care) and control group (50 children who received the hospital routine ward care).

\section{Inclusion Criteria included}

1) Both sexes.

2) Children who were conscious and able to participant in the study.

Exclusion Criteria included:

1) Childrenwho were having postoperative complications after surgery.

2) Children who were conscious and able to participant in the study.

Tools of data collection

Two tools were used to collect the required data for this study.

Tool I: A structured interview questionnaire It was developed by the researcher after reviewing of related literature and it divided into two parts:

\section{Part (I):personal data about children and their} mother's

- It included questions about child's name, age, sex, weight and birth order, and mother's age, education and occupation.

- Part (II): Clinical data questionnaire: It was Include questions about preoperative laboratory investigation, trauma of surgery, types of anesthesia and length of hospital stay. 
Tool II: Sleep assessment scale

The researcher used the Pittsburgh Sleep Quality Index (PSQI) Scale It was developed by Buysse et al., (1989).

It was a self-report questionnaire that assessed sleep quality and sleep pattern. It was adapted by the researcher and translated to arabic language. The questionnaire consisted of 19 individual items and were creating 7 components that produce one global score, it took 5-10 minutes to complete. It differentiates "poor" from "good" sleep by measuring seven domains; subjective sleep quality, sleep latency, sleep duration, habitual sleep efficiency, sleep disturbances, use of sleep medication, and daytime dysfunction before the operation (preoperative period).

Each item is weighted on a 0-3 interval scale. The global PSQI score is then calculated by totaling the seven component scores, providing an overall score ranging from 0 to 21 , where lower scores denote a healthier sleep quality. Whereby3 reflects the negative extreme on the Likert Scale.

A global sum of "5" or greater indicates a "poor" sleep. The PSQI has internal consistency and a reliability coefficient (cronbach's alpha) of 0.83 for its seven components. Numerous studies using the PSQI in a variety of populations internationally have supported high validity and reliability.

\section{Field of the work}

This study was carried out through a period of eight months from the beginning of March (2018) to the ending of October (2018). Aromatherapy massage was applied to the experimental groupby the researcher who was trained by therapist and skilled in aromatherapy massage. The researcher received training on massage in the department of physical medicine that located in the first floor of main university hospital 3 days per week (Sunday, Tuesday and Thursday) for 6 months and the researcher had getting a certificate and had signature by head of department of physical medicine Prof. Dr. / Eman Abass Mahmoud and then signature by saad zaky director of main university hospital. The researcher went to hospital three days per week (Sunday, Monday \& Tuesday), were specified for data collection one times per dayfor three days on the next day morning of second, and fourth of aromatherapy massages for the experimental groupfrom the first postoperative day after 1-4 hours (when the anesthesia had fully worn off) to assess sleep pattern.Two post-test was conducted to assess sleep pattern.The children were receive the hospital routine care as postoperative improve sleep pattern measures, and The time needed for every child was 35 minutes (20-minute foot and hand massage 5 minutes to each extremity) and 15 minutes for filling questionnaire. A 20-minute foot and hand massage (5minutes to each extremity).Pretest was conducted for both experimental and control group. School age children in the control group was received the usual hospital care only and assessed sleep pattern at the same times for the experime group without aromatherapy massage.

\section{Intervention}

\section{Aromatherapy massage}

In the experimental group children was received hand and foot massage beside the hospital routine care as follow aromatherapy massage was used with effleurage, petrissage, friction, joint massage and tapping movements with mild to moderate pressure using lavender oil as the best that helped to relieve postoperative pain (Abbaspoor \& Shahri, 2013). Foot and hand massage technique applied 1-2 drops of essential oil to the reflex point, placed all four fingers flat on the skin. Also using medium pressure rollup onto the finger tips, continued rolling over the finger nails, released and moved forward about $1 / 4$ of an inch, repeat this motion until the reflex point is covered and repeated technique two times per day (Chang, 2004).

- After the intervention in experimental group were evaluated for their outcomes using tool I \&II.

- Children in the control group monitor their sleep pattern by using tool I \&II.

- Finally, the researchers coded and transformed the row data into coding sheets and then, analysis and interpretation of the collected data were done.

\section{Ethical Considerations}

The ethical research considerations in this study was included the following

- Research proposal was approved from ethical committee in the faculty of nursing.

- There was no risk for study subject during application of the research.

- The study was following common ethical principles in clinical research.

- Written consent was obtained from parents that are willing to participation of their children in the study was obtained after explaining the nature and purpose of the study.

- Confidentiality and anonymity was assured.

- Study subject had the right to refuse to participate or withdraw from the study without any rational any time.

- Study subject privacy was considered during collection of data. 


\section{Statistical analysis}

Data entry and data analysis were done using SPSS version 19 (Statistical Package for Social Science). Data were presented as number, percentage, mean, standard deviation. Chi-square test was used to compare qualitative variables. Independent samples t- test was used to compare quantitative variables between two groups. Paired samples t-test was used to compare quantitative variables between pre-test and post-test. P-value considered statistically significant when $\mathrm{P}<0.05$.

\section{Results}

Table(1): Personal data of the studied children.

\begin{tabular}{|c|c|c|c|c|c|}
\hline \multirow[t]{2}{*}{ Personal data } & \multicolumn{2}{|c|}{$\begin{array}{l}\text { Experimental } \\
\operatorname{group}(\mathbf{n}=\mathbf{5 0})\end{array}$} & \multicolumn{2}{|c|}{$\begin{array}{c}\text { Control group } \\
\quad(n=50)\end{array}$} & \multirow{2}{*}{ P-value } \\
\hline & No. & $\%$ & No. & $\%$ & \\
\hline \multicolumn{6}{|l|}{ 1) Child's age / years: } \\
\hline $6-<8$ yrs & 10 & 20 & 19 & 38 & \multirow{3}{*}{0.127} \\
\hline $8-<10 y r s$ & 11 & 22 & 10 & 20 & \\
\hline $10-12 \mathrm{yrs}$ & 29 & 58 & 21 & 42 & \\
\hline Mean \pm SD & \multicolumn{2}{|c|}{$9.74 \pm 2.20$} & \multicolumn{2}{|c|}{$8.84 \pm 2.40$} & 0.056 \\
\hline \multicolumn{6}{|l|}{ 2) Child's Weight/ kg } \\
\hline$<25 \mathrm{~kg}$ & 18 & 36 & 21 & 42 & \multirow{3}{*}{0.660} \\
\hline $25-30 \mathrm{~kg}$ & 16 & 32 & 12 & 24 & \\
\hline$>30 \mathrm{~kg}$ & 16 & 32 & 17 & 34 & \\
\hline Mean \pm SD & \multicolumn{2}{|c|}{$28.36 \pm 8.59$} & \multicolumn{2}{|c|}{$27.54 \pm 7.43$} & 0.611 \\
\hline
\end{tabular}

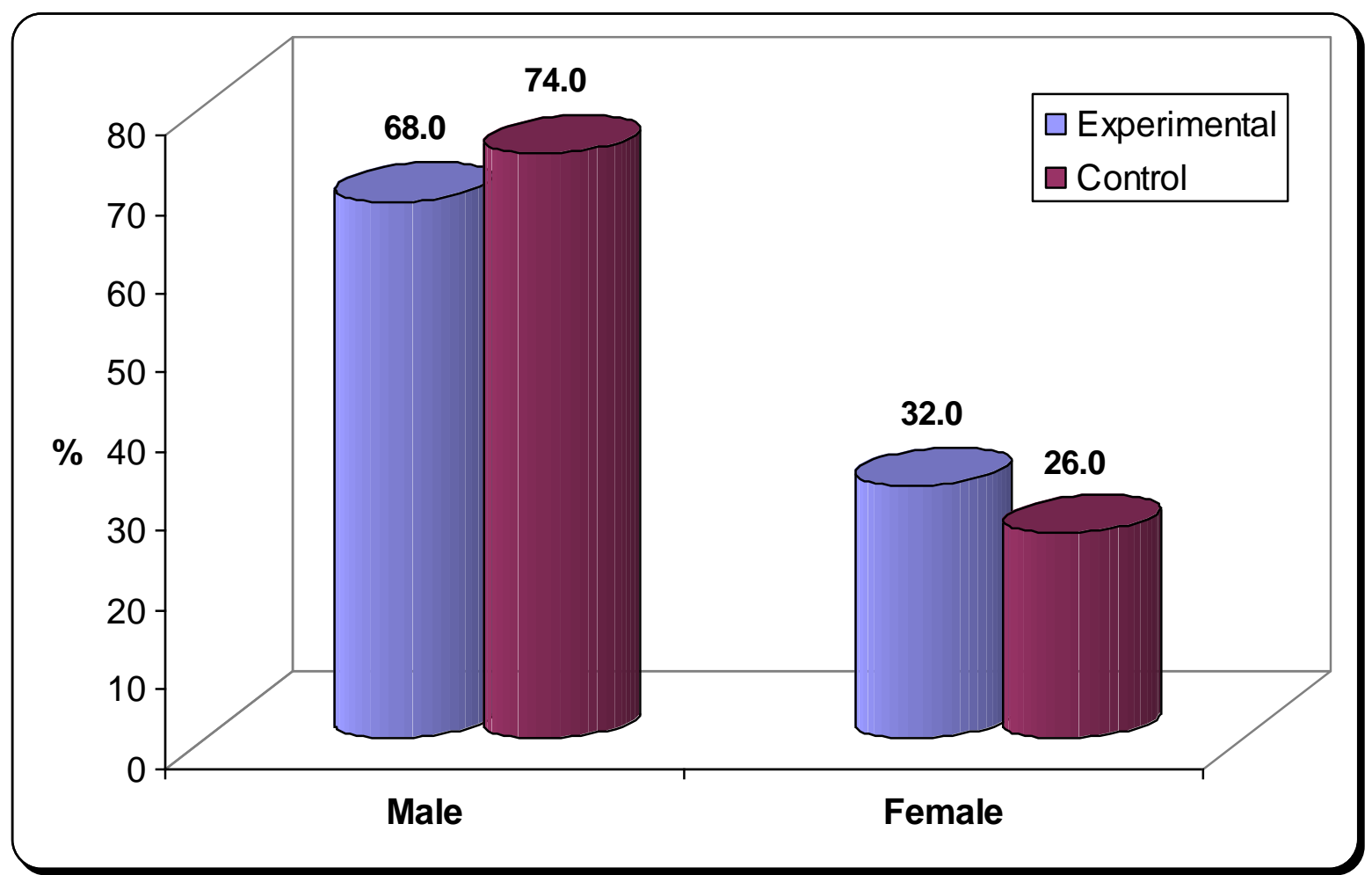

Figure (1): Personal data of the studied children as regard child's sex. 
Table(2):Personal data of the studied children mothers.

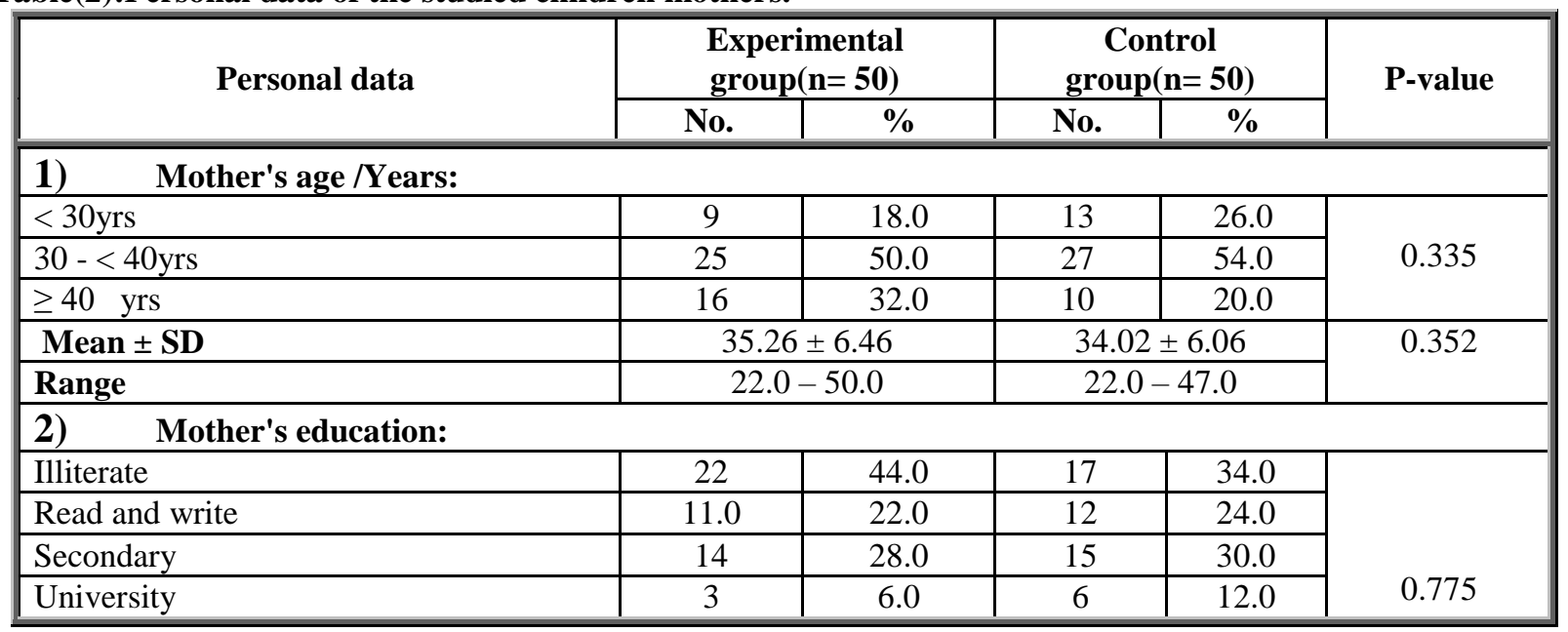

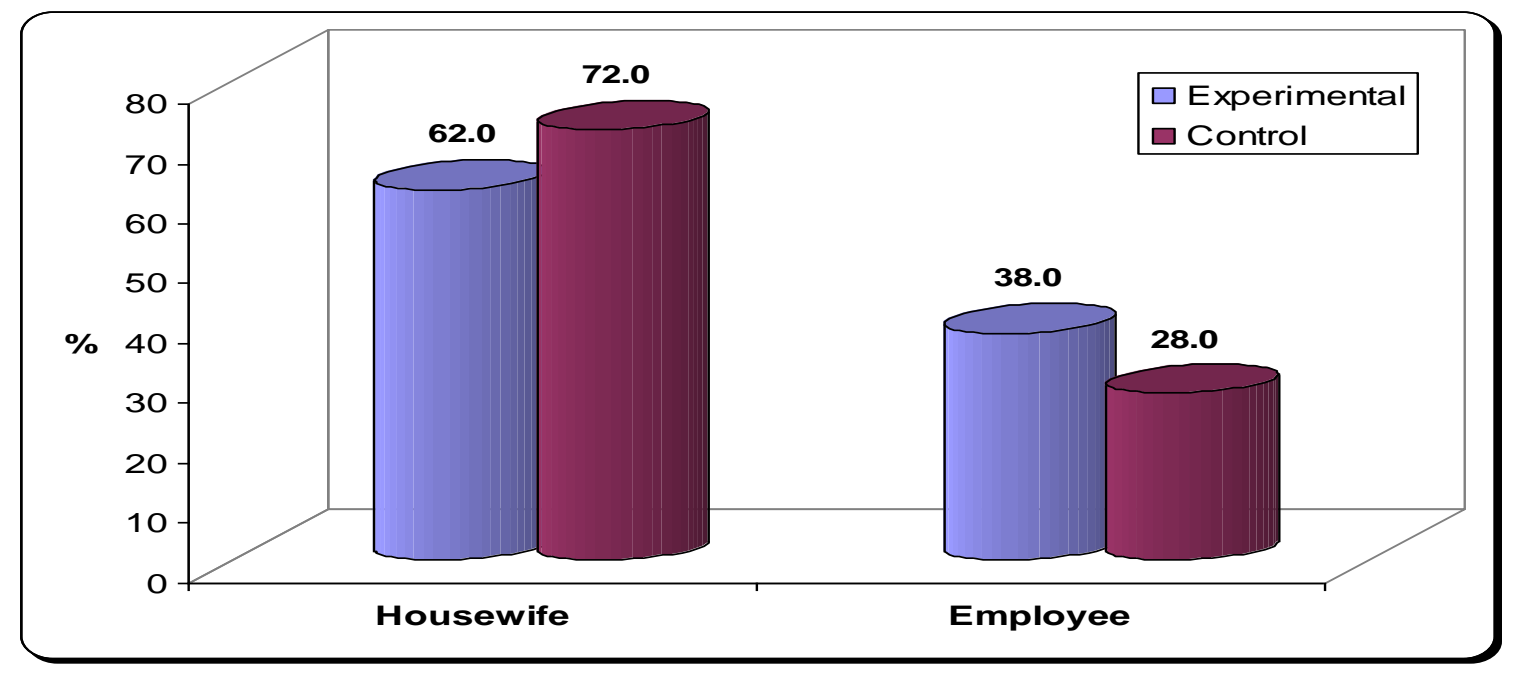

Figure (2):Personal data of the studied mothers as regard mother's occupation.

Table (3): Clinical data of the studied children.

\begin{tabular}{|c|c|c|c|c|c|}
\hline \multirow[t]{2}{*}{ Clinical data } & \multicolumn{2}{|c|}{$\begin{array}{l}\text { Experimental } \\
\text { group }(n=50)\end{array}$} & \multicolumn{2}{|c|}{$\begin{array}{c}\text { Control } \\
\operatorname{group}(n=50)\end{array}$} & \multirow[t]{2}{*}{ P-value } \\
\hline & No. & $\%$ & No. & $\%$ & \\
\hline \multicolumn{6}{|c|}{ 1) Preoperative laboratory investigation: } \\
\hline Blood picture & 50 & 100.0 & 50 & 100.0 & -- \\
\hline Prothrombin time & 50 & 100.0 & 50 & 100.0 & -- \\
\hline Serum sodium \&potassium & 46 & 92.0 & 44 & 88.0 & 0.505 \\
\hline Urea \& keratinized & 46 & 92.0 & 44 & 88.0 & 0.505 \\
\hline \multicolumn{6}{|l|}{ 2) Length of hospital stay } \\
\hline 2 - 3 days & 22 & 44.0 & 24 & 48.0 & \multirow{3}{*}{0.591} \\
\hline $4-5$ days & 19 & 38.0 & 22 & 44.0 & \\
\hline$>5$ days & 9 & 18.0 & 7 & 14.0 & \\
\hline
\end{tabular}




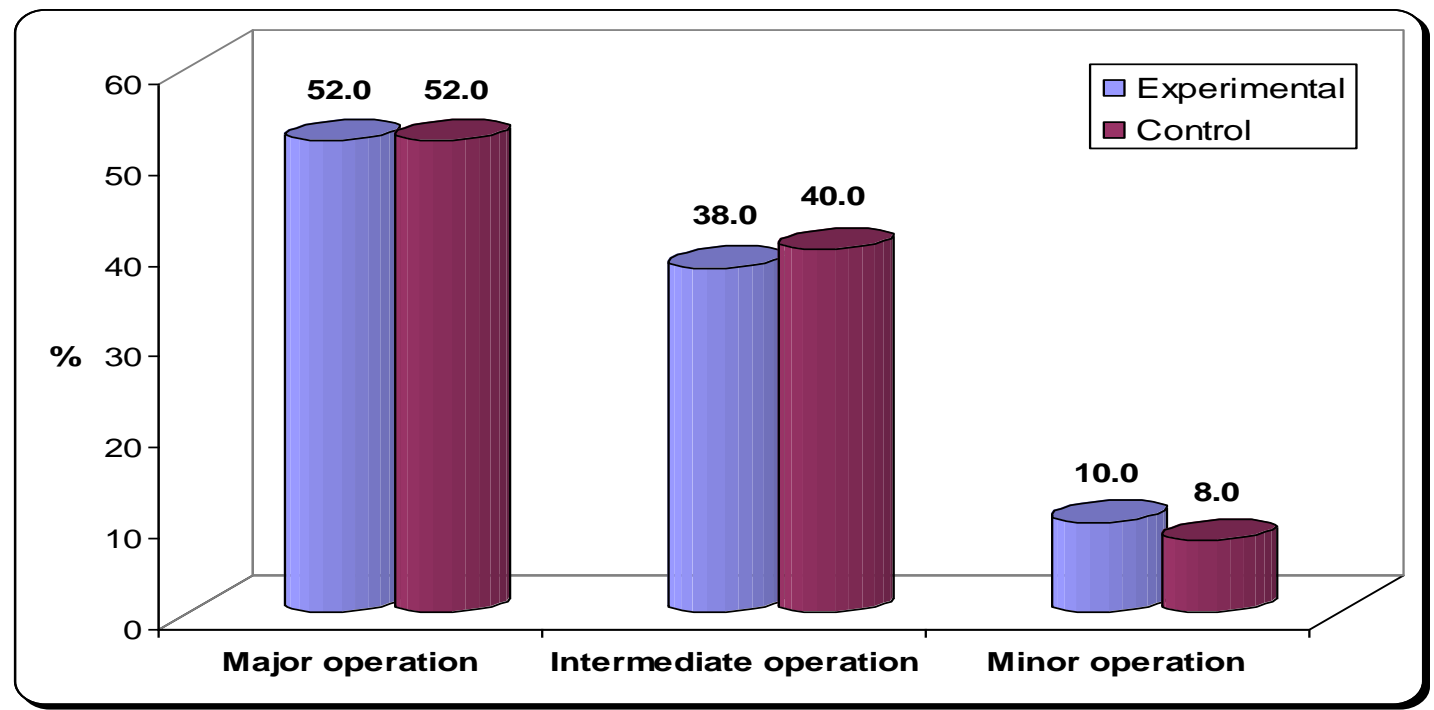

Figure (3)Types of surgery of the studied children in the experimental and control groups.

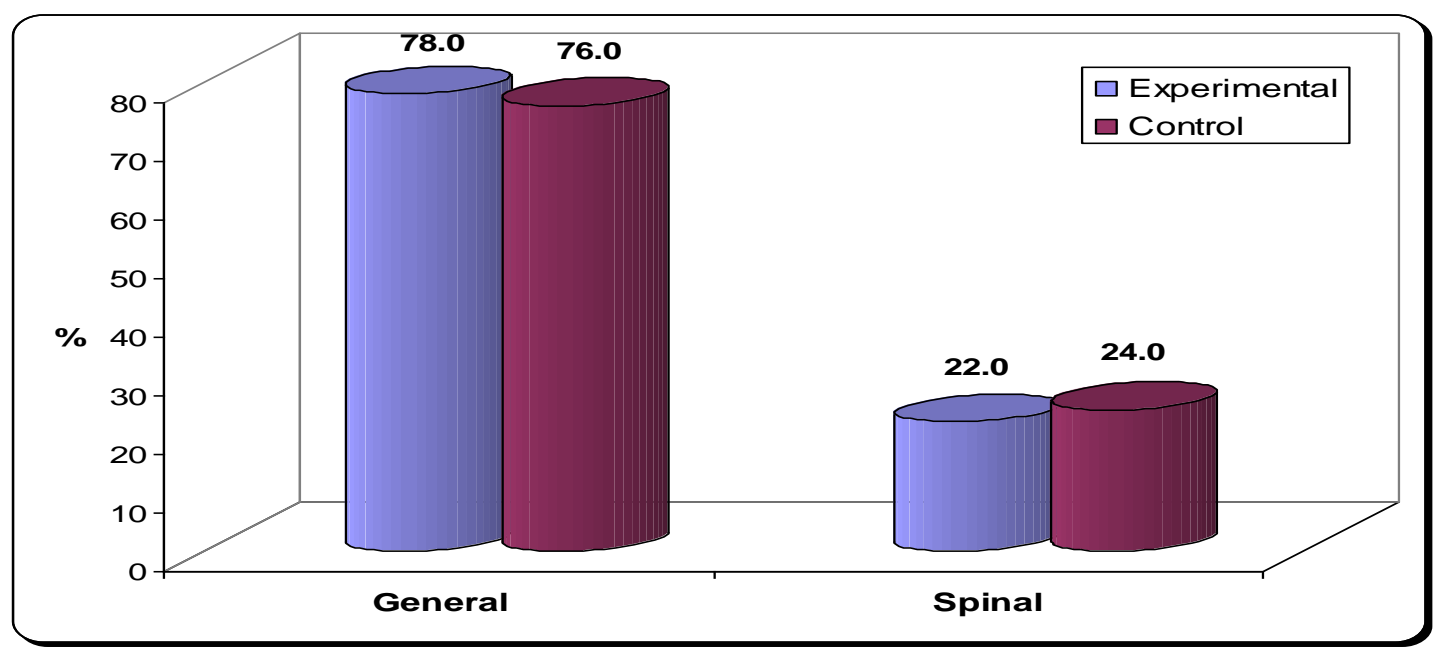

Figure (4):Types of anesthesia of the studied children in the experimental and control groups.

Table (4):Total mean score of the Pittsburgh Sleep Quality Index among children in the experimental and control groups.

\begin{tabular}{|c|c|c|c|}
\hline Pittsburgh Sleep Quality Index & $\begin{array}{l}\text { Experimental } \\
\text { group }(n=50) \\
\end{array}$ & $\begin{array}{c}\text { Control } \\
\text { group }(n=50) \\
\end{array}$ & P-value \\
\hline \multicolumn{4}{|l|}{ 1) Pretest } \\
\hline Mean \pm SD & $11.66 \pm 2.54$ & $13.26 \pm 2.59$ & \multirow{2}{*}{$0.004 *$} \\
\hline Median (Range) & $12.0(7.0-18.0)$ & $13.0(9.0-18.0)$ & \\
\hline \multicolumn{4}{|l|}{ 2) First post } \\
\hline Mean \pm SD & $9.50 \pm 0.97$ & $10.14 \pm 1.01$ & \multirow{2}{*}{$0.000 *$} \\
\hline Median (Range) & $10.0(6.0-12.0)$ & $10.0(8.0-13.0)$ & \\
\hline \multicolumn{4}{|l|}{ 3) Second post } \\
\hline Mean \pm SD & $5.80 \pm 0.70$ & $6.30 \pm 0.68$ & \multirow[b]{2}{*}{$0.000 *$} \\
\hline Median (Range) & $6.0(4.0-8.0)$ & $6.0(5.0-9.0)$ & \\
\hline
\end{tabular}


Table (5): Relation between mean pretest score of sleep pattern and their personal characteristics in the experimental group.

\begin{tabular}{|c|c|c|}
\hline \multirow{2}{*}{ Personal Data } & Experimental group $(n=50)($ Pre test $)$ & \multirow{2}{*}{ P-value } \\
\hline & Mean \pm SD & \\
\hline 1) Child age /Years & & \multirow[t]{4}{*}{$0.005^{*}$} \\
\hline $6-<8$ yrs & $10.30 \pm 2.26$ & \\
\hline $8-<10$ yrs & $10.36 \pm 2.34$ & \\
\hline $10-12$ yrs & $12.62 \pm 2.32$ & \\
\hline \multicolumn{2}{|l|}{ 2) Child sex } & \multirow[t]{3}{*}{0.318} \\
\hline Male & $11.41 \pm 2.58$ & \\
\hline Female & $12.19 \pm 2.43$ & \\
\hline \multicolumn{2}{|l|}{ 3) Child weight / kg } & \multirow[t]{4}{*}{$0.031 *$} \\
\hline$<25 / \mathrm{kg}$ & $10.56 \pm 2.53$ & \\
\hline $25-30 \mathrm{~kg}$ & $11.75 \pm 2.18$ & \\
\hline$>30 \mathrm{~kg}$ & $12.81 \pm 2.48$ & \\
\hline \multicolumn{2}{|l|}{ 4) Child birth order } & \multirow[t]{5}{*}{0.716} \\
\hline First & $11.57 \pm 2.68$ & \\
\hline Second & $11.07 \pm 2.81$ & \\
\hline Third & $12.09 \pm 2.39$ & \\
\hline Fourth or more & $12.09 \pm 2.30$ & \\
\hline
\end{tabular}

Table (6): Relation between mean first posttest score of sleep pattern and their personal characteristics in the experimental group.

\begin{tabular}{|c|c|c|}
\hline \multirow[t]{2}{*}{ Personal Data } & $\begin{array}{c}\text { Experimental group }(n=50)(\text { first } \\
\text { posttest })\end{array}$ & \multirow[t]{2}{*}{ P-value } \\
\hline & Mean \pm SD & \\
\hline \multicolumn{2}{|l|}{ 1) Child age /Years } & \multirow{4}{*}{$0.026^{*}$} \\
\hline $6-<8$ yrs & $8.90 \pm 1.45$ & \\
\hline $8-<10$ yrs & $9.27 \pm 0.90$ & \\
\hline $10-12$ yrs & $9.79 \pm 0.68$ & \\
\hline \multicolumn{2}{|l|}{ 2) Child sex } & \multirow{3}{*}{1.000} \\
\hline Male & $9.50 \pm 1.08$ & \\
\hline Female & $9.50 \pm 0.73$ & \\
\hline \multicolumn{2}{|l|}{ 3) Child weight / kg } & \multirow{4}{*}{0.214} \\
\hline$<25 \mathrm{~kg}$ & $9.22 \pm 1.22$ & \\
\hline $25-30 \mathrm{~kg}$ & $9.50 \pm 0.73$ & \\
\hline$>30 \quad \mathrm{~kg}$ & $9.81 \pm 0.83$ & \\
\hline \multicolumn{2}{|l|}{ 4) Child birth order } & \multirow{5}{*}{0.829} \\
\hline First & $9.36 \pm 1.22$ & \\
\hline Second & $9.50 \pm 0.85$ & \\
\hline Third & $9.45 \pm 0.82$ & \\
\hline Fourth or more & $9.73 \pm 1.01$ & \\
\hline
\end{tabular}


Table (7): Relation between mean second posttest score of sleep pattern and their personal characteristics in the experimental group.

\begin{tabular}{|c|c|c|}
\hline \multirow[t]{2}{*}{ Personal Data } & $\begin{array}{c}\text { Experimental group } \\
(n=50)(\text { second posttest })\end{array}$ & \multirow{2}{*}{ P-value } \\
\hline & Mean \pm SD & \\
\hline \multicolumn{2}{|l|}{ 1) Child age/Years } & \multirow{4}{*}{0.807} \\
\hline $6-<8$ yrs & $6.00 \pm 0.94$ & \\
\hline $8-<10$ yrs & $5.82 \pm 0.60$ & \\
\hline $10-12$ yrs & $5.72 \pm 0.65$ & \\
\hline \multicolumn{2}{|l|}{ 2) Child sex } & \multirow{3}{*}{0.124} \\
\hline Male & $5.91 \pm 0.67$ & \\
\hline Female & $5.56 \pm 0.73$ & \\
\hline \multicolumn{2}{|l|}{ 3) Child weight/ kg: } & \multirow{4}{*}{0.111} \\
\hline$<25 \mathrm{~kg}$ & $6.06 \pm 0.80$ & \\
\hline $25-30 \mathrm{~kg}$ & $5.81 \pm 0.54$ & \\
\hline$>30 \mathrm{~kg}$ & $5.50 \pm 0.63$ & \\
\hline \multicolumn{2}{|l|}{ 4) Child birth order } & \multirow{5}{*}{0.975} \\
\hline First & $5.86 \pm 0.77$ & \\
\hline Second & $5.71 \pm 0.47$ & \\
\hline Third & $5.82 \pm 0.98$ & \\
\hline Fourth or more & $5.82 \pm 0.60$ & \\
\hline
\end{tabular}

Table (1): Shows the personal data of the studied children. It was found that more than half $(58 \%)$ of studied children in the experimental group was in the age group from 10 - 12 years compared to more than two- fifths $(42 \%)$ of children in the control group with mean age was $9.74 \pm 2.20$ in the experimental group and $8.84 \pm 2.40$ in the control group.

In addition to child's weight more than one- third $(36.0 \%)$ of children in the experimental group their weight was $<25 \mathrm{~kg}$ compared to more than two-fifths $(42 \%)$ in control group. Children's mean weight was $28.36 \pm 8.59$ in the experimental group and $27.54 \pm$ 7.43 in the control group.

Figure (1): As regards child's sex more than two thirds $(68 \%)$ of children in the experimental group were male compared to $74 \%$ in the control group.

Table (2): Shows the personal data of the studied children mothers. It was indicated that $50 \%$ of the studied mother in the experimental group their age ranged from $30-<40$ years compared to $54 \%$ in the control group. The mean age was $35.26 \pm 6.46 \mathrm{v}$. s. $34.02 \pm 6.06$ respectively in the experimental and control groups. Moreover regarding mother's education; more than two- fifths (44\%) of mother's in the experimental group were illiterate compared to more than -one third (34\%) in the control group.

Figure (2): Regarding mother's occupation; more than two- thirds $62 \%$ of the mother's in the experimental group were housewives compared to $72 \%$ in the control group. Like wise the statistical significant differences were not found between the two groups as regard personal data of the studied mothers.

Table (3): Regarding preoperative laboratory investigation $100 \%$ of both groups were doing blood picture and prothrombin time. Concerning length of hospital stay more than two- fifths (44\%) in the experimental group stayed from 2-3 days at hospital compared to nearly half (48\%) in the control group. No statistically significant differences were found between the two groups as regards the clinical data of the studied children.

Figure (3): Types of surgery of the studied children in the experimental and control group. It was noticed that $(52 \%)$ of both groups had major operation. While more than one -third $(38 \%)$ in the experimental group compared to more than twofifths $(44 \%)$ in the control group had intermediate operation. Also (10\%) in the experimental group compared to $(8 \%)$ in the control group had minor operation. No statistically significant differences was found between the two groups concerning trauma of surgery of the studied children.

Figure (4): Types of anesthesia of the studied children in the experimental and control group. It was indicated that the majority of both groups were receiving general anesthesia $(78 \%$ and $76 \%)$ 
respectively in the experimental and control groups. No statistically statistical significant difference was found between the two groups as regards types of anesthesia of the studied children (P-value $=0.812$ ).

Table (4): Shows the total mean score of the Pittsburgh Sleep Quality Index among children in the experimental and control groups. It was noticed that statistically significant differences were found between children in the two groups in the pretest, first posttest, and second posttest (P-value = $0.004,0.004,0.000$ respectively) in the experimental and control groups. Also statistically significant differences was found between pretest and first posttest $(\mathrm{P} 2$-value $=0.000)$ and between first posttest and second posttest $(\mathrm{P} 2$-value $=0.000)$ in the experimental group and in the control group.

Table (5): Presents relation between mean pretest score of sleep pattern and their personal characteristics in the experimental group. It was found that statistically significant differences were found between pretest score of sleep pattern of child age and child weight while there were no statistically significant differences were found between pretest score of sleep pattern of child sex and child birth order.

Table (6): Presents relation between mean first posttest score of sleep pattern and their personal characteristics in the experimental group. It was found that statistically significant differences were found between first posttest score of sleep pattern child age while there were no statistically significant differences were found between first posttest score of sleep pattern of child weight, child sex. and child birth order

Table (7): Presents relation between mean second posttest score of sleep pattern and their personal characteristics in the experimental group.. It was found that no statistically significant differences were found between second posttest mean score of sleep pattern of child weight, child sex. child age, and child birth order,

\section{Discussion}

Sleep is an essential component of health and is related to physical and psychological well-being. Sleep disorder is one of the main problems in children after surgery and pediatric patients in hospitals; however, there is still a lack of knowledge in nursing about the effectiveness of sleep-promoting interventions Hellstrom et al., (2011). Poor sleep pattern can lead to adverse effects on health and recovery. Aromatherapy is one of the nonpharmacological methods for improving sleep pattern and lavender has analgesic properties. Aromatherapy massage with lavender oil is a kind of method for improving sleep pattern after surgery Lytle et al., (2014).

Moreover, control of the pediatric patient's sleeping environmental factors during hospitalization and management of physiological, psychological symptoms are improving the sleep quality and early recovery in post-operative pediatric patients Huang et al., (2011).In this regard, a recent interest to study the role of massage intervention as a part of the complementary nursing care for post-operative children, to manage their sleep disturbances Cutshall et al., (2010).

The findings of the study revealed that majority of child's age near two- thirds in the experimental group as well as more two- fifths in the control group were in the age group of $10-12$ years. Majority of children in the experimental group more than twothirds and majority of control group were males. More than one- third of child's weight in the experimental group while more than two fifths in the control group had weight $<25 \mathrm{~kg}$. Near two - fifths in the experimental group as well as near one- third in the control group were child's birth order. These findings consistency with Al-Rafay \& Ali, (2013) who found that no significant differences existing between characteristics of children in both control and experimental groups. Moreover, all children were at the stage of elementary school. This sums up that more homogeneity between the two involved groups children.

In present study the personal data of the studied children mothers half of mother's age in the experimental group compared to more than half in the control group were in the age group of $30-<40$ years. More than two- fifths of mother's education in the experimental group compared to more than one third in the control group had illiterate. While more than two - thirds in the experimental group compared to Majority in the control group were housewife. These finding agreement with Marline \& Larine, (2008). Who found that the demographic variables which includes age, gender, marital status, social support, duration of stay, reason for staying, and diseases do not have any association with the quality of sleep among the pediatric.

Findings of the present study revealed that there were statistically significant differences were found between children in the two groups in the pretest, first posttest, and second posttest in the experimental and control groups. These findings were in agreement with. Moeini et al., (2010) \& Cho et al., (2013) who found that the quality of sleep pattern increased in children who received aromatherapy massage. And also. Chien et al., (2012) who found that lavender aromatherapy massage lead to a significant 
improvement in sleep pattern. Aromatherapy is used for depression, anxiety, relaxation and disorders related with sleep and stress.

Findings of the present study revealed that there were statistically significant differences was found between pretest and first posttest and between first posttest and second posttest in the two groups. These finding was go on line with Marline et al., (2008) who found that a significant difference was found between mean quality of sleep score (Global PSQI score) in the posttest was much lesser than the pretest score. This projects that aromatherapy was very effective in improving the qulaity of sleep pattren among the children. And also agree with Naja et al., (2014) who observed that significant improvements of relaxation and night sleep hours along 3 nights of the study among pediatric sleeping more hours at night, and falling asleep early. This might explain the benefits derived from massage intervention to improve sleep pattern which reduce the sensitivity to sleep disturbances, depression, and anxiety levels. Foot and hand massage appears to be an effective, inexpensive, low-risk, flexible, relaxation and easily applied strategy for postoperative sleep pattern.

Regarding Types of surgery of the studied children in the experimental and control group. No statistically significant found between the two groups concerning Types of surgery of the studied children. In my opinion disagree with these current study aromatherapy massage with lavender oil in minor operation more effective in improving sleep pattern than intermediate operation and improving sleep pattern than major operation.

As regard types of anesthesia of the studied children in the experimental and control group. Findings of the present study revealed that no statistically statistical significant difference was found between the two groups as regards types of anesthesia of the studied children. These finding was go on line with Soltani et al., (2013) who found that children recovering from tonsillectomy children treated with lavender aromatherapy slept better and required more than two fifth less acetaminophen than children in the control group. Massage group had significant decrease sleep disrupt, anxiety, and tension, stress after the intervention and they were highly satisfied. In the present study, preoperative laboratory investigation all of both groups were doing blood picture and prothrombin time. No statistically significant differences were found between the two groups as regards preoperative laboratory investigation and length of hospital stay of the studied children. In my opinion and experience agree with these results all children admission to hospital make all investigation to get correct diagnosis, good operation for improving sleep pattern and providing suitable nursing care.

Regarding length of hospital stay more than twofifths in the experimental group stayed from 2-3 days at hospital compared to nearly half in the control group. In my agree with these finding use of aromatherapy massage with lavender essential oil its relaxing, sedative effects and had a positive effect on the quality of sleep and anxiety this help recovery and hospital stay in the experimental group less than control group.

\section{Conclusion}

From the current study results it was concluded that: Applying aromatherapy massage with lavender oil using a 20 minutes foot and hand massage intervention for school age children in the postoperative period was effective in improving sleep pattern ..A statistical significant differences was found between experimental and control groups regarding sleep pattern score in first posttest, and second posttest among the studied children in the experimental and control group.

\section{Recommendations}

Based on the results of the current study, the following recommendations are suggested.

1. Educational programs should be provided to increase knowledge and skills for nurses and parents in applying nonpharmacological intervention to improve sleep pattern in children during any invasive surgical procedures.

2. Increasing the likelihood use of foot and hand massage with lavender oil should be accepted as routine nursing interventions for sleep pattern management in children.

3. Using aromatherapy massage as routine interventions for improving postoperative poor sleep pattern in children.

\section{References}

1. Akca Ay F., (2012): Basic Concepts and Skills in Health Practice. 4th edn. Nobel Bookstore, Istanbul.

2. Hajibagheri A., Babaii A., \& AdibHajbaghery M., (2014): Effect of Rosa damascene aromatherapy on sleep quality in cardiac patients: a randomized controlled trial. Complementary Therapies in Clinical Practice; 20: Pp:159-63.

3. Lytle J., Mwatha C., \& Davis K., (2014): Effect of lavender aromatheraapy on vital signs and perceived quality of sleep in the 
intermediate care unit: a pilot study.American Journal of Critical Care;23: Pp:24- 29.

4. Ozdemir H., \& Oztunc G., (2013): Aromatherapy in Nursing Practice:Review. Journal of Turkey Clinical Nursing Science. 5: Pp:98-104.

5. Bikmoradi, A., Seifi, Z., Poorolajal, J., Araghchian, M., Safiaryan, R., \& Oshvandi, K., (2014): Effect of inhalation aromatherapy with lavender essential oil on stress and vital signs inpatients undergone coronary artery bypass surgery: a single blinded randomized clinical trial. ComplementaryTherapies in Medicine.23::331-38. DOI: 10.1016/j.ctim.2014.12.001.

6. Cho M., Min E., Hur M., \& Lee M., (2013): Effects of aromatherapy on the anxiety, vital signs, and sleep quality of percutaneous coronary intervention patients in intensive care units. Evidence-Based Complementary and Alternative Medicine; 2013; 2013:381381. doi: $10.1155 / 2013 / 381381$.

7. Moeini M., Khadibi M., Bekhradi R., Ahmad, Mahmoudian S., \& Nazari F., (2010): Effectof aromatherapy on the quality of sleep in ischemic heart disease patients hospitalized in intensive care units of heart hospitals of the Isfahan University of Medical Sciences. Iranian Journal of Nursing and Midwifery Research; Pp:234-39.

8. Fayazi S., Babashahi M., \& Rezaei M., (2011): The effect of inhalation aromatherapy on anxiety level of patients in preoperative period. Iran J Nurs Midwifery Res. 16:Pp:27883.

9. Kurt S., \& Enc N., (2013): Sleep problems in critical care patientsand nursing care. Turkish Journal of Cardiovascular Nursing; 4:/*-Pp:1-8.

10. Babaee, S., Shafiei, Z., Sadeghi, M., Yazdan Nik, A., \&Valiani, M., (2012): Effectiveness of massage therapy on the mood of patients after open-heart surgery. Iran J Nurs Midwifery Res; 17 (2 suppl 1): S1P: 20S4.

11. Mardasi Najar Sh., \& Haghighizadeh M., (2013): The Effect of Foot Massage on Sleep Disorders among Mothers in Postpartum Period. Iranina Journal of Obstetrics Gynecology and Infertility 16 (73): Pp :19-28. (Persian).

12. Terri, K., \& Susan, C., (2013): Essentials of pediatric nursing, Pain Management in Children, chapter 14, 2nd edition, Lippincott Williams \& WilkinPp.553-91.
13. Browne, N., \& Flanigan, L., (2007): Nursing care of the paediatric surgical patient. $2^{\text {nd }} e d$, Philadelphia: Jones and Bartlett Publication Pp:774.

14. Buysse D., Reynolds C., Monk T., Berman S., \& Kupfer D., (1989): The Pittsburg sleep quality index: a new instrument for psychiatric practice and research. Psychiastry Res. 28 (2). Pp:193-213. PubMed | Google Scholar

15. Mazlum Toghian N., Banihashem A., \& Behnam H., (2013): The effect of massage therapy on chemotherapy-induced nausea and vomiting in pediatric cancer, Iran $\mathrm{J}$ Nurs Midwifery Res; 18(4). Pp: 280-84.

16. Abbaspoor Z., \& Shahri M., (2013): Lavender aromatherapy mass ages in reducing labor pain and duration of labor: randomized controlled trial. African Journal of Pharmacy and Pharmacology7 (8), Pp: 426-30.

17. Chang S., (2004): Effect of aroma hand massage on pain, state anxiety and depression in hospice patients with terminal cancer. Palliative Medicine.

18. Hellstrom, A., Fagerstrom, C., \& Willman, A., (2011): Promoting sleep by nursing interventions in health care settings: a systematic review. Sweden. Worldviews Evid Based Nurs., 8(3), Pp:128-42. doi: 10.11 II/j.1741-6787.2010.00203

19. Huang, C., Huang, T., Hwang, S., \& Liao, W., (2011): A Systematic Review of Sleep Patterns and Factors That Disturb Sleep After Heart Surgery. The Journal of Nursing Research, 19(4),Pp: 275 - 88.

20. Cutshall, S., Wentworth, L., Engen, D., Sundt, T., Kelly, R., \& Bauer, B., (2010): Effect of massage therapy on pain, anxiety, and tension in cardiac surgical patients: a pilot study. United States. Complement TherClin Pract, 16(2),Pp: 92-5. doi: 10.1016/j.ctcp.2009.10.006.

21. Al-Rafay S., \& Ali A., (2013): Effect of Massage on Sleep Disturbances of Children after Abdominal Surgeries.J Am Sci 2013;9(12):Pp:626-32]. (ISSN: 1545-1003). http://www.jofamericanscience.org. 81

22. Marline C., Smith \& Larine Kyle, (2008): Holistic foundation of aromatherapy for nursing. Journal of holistic nursing practice. Jan/Feb; 22(1);Pp:3-9.

23. Chien L., Cheng S., Liu C., (2012): The effect of lavender aromatherapy on autonomic nervous system in midlife women with insomnia. Evidence-Based Complementary and 
Alternative Medicine; 2012;2012:740813, 8 pages. doi:10.1155/2012/740813.

24. Marline C., Smith \& Larine Kyle, (2008): Holistic foundation of aromatherapy for nursing. Journal of holistic nursing practice. Jan/Feb; 22(1);Pp: 3-9.

25. Naja Z., Tagharrobi Z., Shahriyari-KaleMasihi M., (2014): Effectof aromatherapy with lavender on sleep quality among patients under going hemodialysis. Feyz Journal of Kashan University of Medical Sciences;18: Pp:145150.

26. Soltani, S., Soheilipour, V., Hajhashemi, G., Asghari, M., Bagheri, \& M., Molavi, (2013): "Evaluation of the effect of aromatherapy with lavender essential oil on post-tonsillectomy pain in pediatric patients: a randomized controlled trial," International Journal of Pediatric Otorhinolaryngology,vol.77,no.9pp:1579-81.

27. Badin .E, Haddad C., \& Shatkin J., (2016): Insomnia, the sleeping giant of pediatric public health. Curr Psychiatry Rep.; ArticleID 26993792. 